Artigo recebido em $10 / 03 / 2014$

Aprovado em

$30 / 04 / 2014$

MARCELO TRÄSEL

Pontifícia Universidade Católica do Rio Grande do Sul - marcelo@trasel. com.br

Jornalista, mestre em Comunicação e Informação e doutorando em Comunicação Social.

Professor-assistente na Famecos/PUCRS.

Conselheiro fiscal da Associação Brasileira de Jornalismo Investigativo.

\section{Jornalismo guiado por dados: aproximações entre a identidade jornalística e a cultura hacker ${ }^{1}$}

\section{Marcelo Träsel}

\section{Resumo}

O Jornalismo Guiado por Dados é uma prática de Jornalismo em Bases de Dados em vias de adoção por redações de todo o mundo, desde meados dos anos 2000. Tratase de um desenvolvimento dos conceitos de Jornalismo de Precisão e Reportagem Assistida por Computador, propostos inicialmente nos anos 1970 e impulsionados pelo processo de digitalização das redações e pela adoção de políticas de acesso à informação por governos e instituições. O trabalho levanta a hipótese de que o Jornalismo Guiado por Dados se configura como uma imbricação entre a cultura profissional dos jornalistas e a cultura hacker. Os resultados da etapa preliminar de uma pesquisa etnográfica realizada entre jornalistas brasileiros em novembro e dezembro de 2012 sugerem que os jornalistas guiados por dados compartilham algumas práticas e valores com os membros da cultura hacker.

Palavras-chave

Jornalismo Guiado por Dados, Reportagem Assistida por Computador, Etnografia.

\begin{abstract}
Data Driven Journalism is a practice in the process of adoption by newsrooms around the world since the mid 2000s. It is a development of the concepts of Precision Journalism and Computer-Assisted Reporting, initially proposed in 1970, which has gained momentum by the digitization process of newsrooms and the adoption of policies on access to information by governments and institutions. The paper hypothesizes that Data Driven Journalism is configured as an overlap between the professional culture of journalists and hacker culture. The results of the preliminary stage of an ethnographic study of Brazilian journalists, carried forward in November and December of 2012, suggest that data-driven journalists do share some common practices and values with the members of hacker culture.
\end{abstract}

Keywords

Data-driven Journalism, Computer-Assisted Reporting, Ethnography.

1- Artigo apresentado ao Grupo de Trabalho Estudos de Jornalismo do XXII Encontro Anual da Compós, na Universidade Federal da Bahia, Salvador, de 04 a 07 de junho de 2013. 


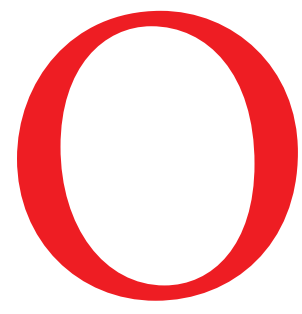

termo

Jornalismo

Guiado por Dados

(JGD)

compreende

diversas

práticas

profissionais,

cujo

ponto em comum é o uso de dados como

principal fonte de informação para a produção de notícias. Barbosa e Torres (2012) consideram o fenômeno como pertencente ao paradigma Jornalismo Digital em Bases de Dados (JDBD), caracterizando-o como uma extensão ou ampliação das práticas de JDBD. Conforme os autores, o conceito de JDBD compreende:

O modelo que tem as bases de dados como definidoras da estrutura e da organização, bem como da composição e da apresentação dos conteúdos de natureza jornalística, de acordo com funcionalidades e categorias específicas, que também vão permitir a criação, a manutenção, a atualização, a disponibilização, a publicação e a circulação de cibermeios dinâmicos em multiplataformas. (BARBOSA e TORRES, 2012, p. 3)

O JGD tem por objetivo, justamente, a produção, tratamento e cruzamento de grandes quantidades de dados, de modo a permitir maior eficiência na recuperação de informações, na apuração de reportagens a partir de conjuntos de dados, na circulação em diferentes plataformas (computadores pessoais, smartphones,

2- Um mash-up é compreendido, no contexto da informática, como uma aplicação para a Web produzida pelo amálgama de duas ou mais fontes diferentes, gerando um terceiro produto. Em geral, as fontes colocam os dados voluntariamente à disposição. tablets), na geração de visualizações e infografias. Principalmente, as técnicas de JGD permitem ao jornalista encontrar informação com valor noticioso em bases de dados com milhares ou milhões de registros, dificilmente manejáveis sem a ajuda de computadores. Facilitam, ainda, o cruzamento de diferentes bases de dados, para a produção de novo conhecimento sobre a sociedade, a ser apresentado em narrativas que se estendem dos jogos eletrônicos e mash$u p s^{2}$ às matérias tradicionais em texto, audiovisual e imagem.

Conforme Gray et al. (2012), a primeira referência a Data Journalism (Jornalismo de Dados), termo que derivou em Data-Driven Journalism (Jornalismo Guiado por Dados), ocorreu no artigo "A fundamental way newspapers sites need to change", publicado pelo programador Adrian Holovaty (2006) em seu website pessoal. Na proposta, Holovaty recomenda a incorporação de técnicas de gerenciamento de bases de dados ao cotidiano das redações, como forma de facilitar o reaproveitamento das informações coletadas no trabalho diário de reportagem.

So much of what local journalists collect day-to-day is structured information: the type of information that can be sliced-and-diced, in an automated fashion, by computers. Yet the information gets distilled into a big blob of text - a newspaper story - that has no chance of being repurposed. (HOLOVATY, 2006)

A alternativa a este problema seria criar rotinas produtivas cujo objetivo seja o desenvolvimento de bases de dados estruturados sobre todos os assuntos de interesse de uma determinada redação. Uma vez que as bases de dados estejam disponíveis aos jornalistas, podem ser reaproveitadas na criação de "diferentes configurações para as informações e, inclusive, novas tematizações ou elementos conceituais para a organização e apresentação dos conteúdos" (BARBOSA, 2007, p. 130), como exige o paradigma JDBD. 
Para além dos aspectos técnicos e narrativos, entretanto, o JGD busca essencialmente introduzir a racionalidade científica nas rotinas de produção jornalística. Na obra Precision Journalism (Jornalismo de Precisão), escrita entre 1969 e 1970, o jornalista Philip Meyer propunha o uso de técnicas quantitativas das ciências sociais para que os repórteres errassem com menor frequência na apreensão dos fatos. Aliando os recursos da sociologia com a rapidez de cálculo dos computadores, seria possível um retorno da objetividade às redações, nas quais muitos jornalistas haviam derivado para abordagens interpretativas com o Novo Jornalismo.

Instead of starting from a base of personal conviction, ideology, or conventional wisdom we can start with intensive and systematic factfinding efforts. Such a suggestion may seem to be a plea for a reactionary return to the old ideal of objectivity, but it has this difference: instead of reporting competing viewpoints for what they are worth, we could make an effort to determine just what they are worth. It is necessary to reduce the size of the leap from fact to interpretation, and to find a more solid base of fact from which to leap. (MEYER, 1973, p. 13)

A meta da aplicação de técnicas como amostragem, questionários, estatística e análise fatorial, entre outras, era transcender a preocupação com a objetividade como mero "ritual estratégico" (TUCHMAN, 1993) contra críticas internas e externas ao trabalho jornalístico, buscando, em lugar disso, uma objetividade de fato. Noutras palavras, os primeiros adeptos do Jornalismo de Precisão viam as técnicas das ciências sociais como um caminho para aproximar o jornalismo o máximo possível da verdade.

Há certa proximidade entre a proposta de Meyer e a perspectiva de Park (1972), que situa o jornalismo a meio caminho entre o senso comum e o saber científico. O primeiro é baseado na experimentação direta dos fenômenos através dos sentidos, o segundo, na sistematização e ordenação dos fenômenos.

O "conhecimento de" (senso comum) pode ser compartilhado apenas parcialmente pela linguagem, enquanto do "conhecimento acerca de" esperase uma universalidade (ciência). O conhecimento concretizado em forma de notícias se situaria em algum ponto do continuum entre o senso comum e a ciência. Seria um tipo de senso-comum transformado por técnicas narrativas num "conhecimento de" comunicável a toda uma sociedade: “...a notícia realiza, de certo modo, para o público, as mesmas funções que realiza para o indivíduo; isto é, não somente o informa como principalmente o orienta, inteirando cada um e todos do que está acontecendo" (PARK, 1972, p. 176).

Meditsch (1997) também vê no jornalismo uma forma de conhecimento posicionada entre a ciência e o senso comum. Tenderia, porém, para este último, visto que sua direção é a de universalizar, não a de especializar. Enquanto forma de conhecimento, o jornalismo sofre duas críticas por parte da academia: falta de rigor analítico e incapacidade de revelar o novo.

Isto se deve ao fato de não gerar novas leis universais através da análise sistemática de fenômenos, mas revelar singularidades a partir do senso comum, 
ao destacar os aspectos de determinado acontecimento que o contrariam:

É o fato de operar no campo lógico da realidade dominante que assegura ao modo de conhecimento do Jornalismo tanto a sua fragilidade quanto a sua força enquanto argumentação. É frágil, enquanto método analítico e demonstrativo, uma vez que não pode se descolar de noções pré-teóricas para representar a realidade. É forte na medida em que essas mesmas noções pré-teóricas orientam o princípio de realidade de seu público, nele incluídos cientistas e filósofos quando retornam à vida cotidiana vindos de seus campos finitos de significação. (MEDITSCH, 1997) $)^{3}$

Noutras palavras, nas sociedades contemporâneas, o jornalismo, embora não seja nem senso comum, nem ciência, dirige a percepção da realidade em que estes dois tipos de conhecimento se baseiam. O Jornalismo de Precisão e, por extensão, o JGD, seu derivado direto - tem por objetivo impulsionar o jornalismo para longe do senso comum, em direção à ciência, através da aplicação de tecnologias e métodos da informática (MEYER, 1999). O ideal por trás deste projeto, nascido no âmbito da cultura profissional jornalística, é o de uma imprensa capaz de dirigir a percepção da realidade social de maneira independente de preconceitos, vieses e ideologias, por meio da aplicação do pensamento tecnológico às rotinas produtivas. Neste aspecto, o JGD filia-se ao imaginário da cibercultura que passou a predominar, ao menos no Ocidente, a partir do século XX (RÜDIGER, 2008). uma disseminação modesta. O termo "Jornalismo de Precisão" acabou sendo abandonado em favor de "Reportagem Assistida por Computador" (RAC), do inglês Computer-Assisted Reporting (CAR). Estas práticas receberam novo impulso nas redações na década de 2000 devido, em primeiro lugar, ao desenvolvimento de ferramentas gratuitas e abundantes para análise de bases de dados e, em segundo lugar, à adoção de políticas de acesso à informação por parte de governos e organizações, que passaram a permitir o acesso a suas bases de dados nos últimos anos (ANGÉLICO, 2012). Na primeira década dos anos 2000 , as expressões "Jornalismo de Dados" ou “Jornalismo Guiado por Dados" passaram a ser mais comuns para se referir a esse conjunto de rotinas produtivas.

A premissa deste trabalho é que o JGD se constitui como uma nova formação na cultura da profissão jornalística, engendrada ao longo das últimas décadas pela informatização progressiva das rotinas produtivas nas redações, pela disponibilidade de ferramentas analíticas acessíveis ao público leigo, pela adesão de instituições e governos a políticas de acesso à informação e pela imersão dos jornalistas contemporâneos na cibercultura.

\section{A cultura profissional dos jornalistas e a cultura hacker}

Os aspectos mais importantes do JGD não são as formas de uso da tecnologia, ou as características materiais dos produtos de suas rotinas produtivas, mas sim a potencialização da capacidade do repórter 
para identificar notícias em grandes volumes de dados. Vendo bem, no JGD, as planilhas eletrônicas, bancos de dados e aplicativos para tratamento estatístico não são substitutos das habilidades dos repórteres, mas instrumentos de ampliação do "faro" jornalístico.

Nesta cultura profissional, as técnicas jornalísticas são vistas como habilidades inerentes ao espírito humano (DINES, 1986; TRAQUINA, 2005). Podese até mesmo argumentar que, para a cultura profissional jornalística, estas habilidades estão ligadas biologicamente aos repórteres, uma vez que a capacidade de identificar valor-notícia em acontecimentos do cotidiano é comumente referida como "faro jornalístico", no jargão das redações. Além disso, os jornalistas são denominados pelos próprios membros deste grupo social como "cães de guarda" da democracia. Neste contexto, o computador é muitas vezes considerado um intruso, um elemento que prejudica o trabalho do repórter ao se intrometer entre sua capacidade de percepção especial dos acontecimentos e do mundo.

Entretanto, os proponentes do JGD costumam reiterar o "faro jornalístico" como uma capacidade do ser humano, que apenas é auxiliada pela tecnologia. Planilhas eletrônicas e ferramentas de visualização de dados permitem enxergar "a olho nu" correlações e tendências presentes em grandes volumes de dados, como todos os crimes cometidos numa grande metrópole durante um ano inteiro, ou todos os pagamentos realizados por um governo estadual num mandato. As ferramentas de computação agilizam o trabalho de fazer correlações entre dados brutos, sem prejuízo para o resultado final em termos jornalísticos. $\mathrm{Ou}$, antes, qualquer prejuízo ao resultado final é tão atribuível ao uso de computadores quanto uma notícia pobremente redigida é atribuível ao fato de ter sido digitada numa máquina de escrever. A qualidade da reportagem depende do talento ou disposição do repórter na apuração e redação da notícia, prejudicado ou não pelas condições organizacionais da redação na qual trabalha - em termos de recursos materiais e temporais para o bom desempenho das funções - e não da interferência da tecnologia.

Paul Bradshaw, jornalista e promotor do JGD, já criticava em 2010, num evento da associação Digital Editors Network britânica, a "pornografia informacional" (data porn), isto é, a tendência a buscar números chocantes ou criar visualizações que pouco contribuem para a narrativa de um acontecimento. $\mathrm{Na}$ mesma ocasião, criticou a "jornorréia informacional" (data churnalism ${ }^{4}$ ), isto é, a propensão a produzir notícias a partir de bases de dados sem a contextualização ou apuração adequadas (OLIVER, 2010). A cautela em relação ao abuso ou ingenuidade na aplicação de técnicas do JGD às rotinas produtivas do jornalismo é uma constante em manifestações de profissionais da área por ocasião de eventos públicos, ou em websites pessoais e noticiário especializado - um alerta, por sinal, já presente na obra pioneira de Meyer (1973).

A observação das manifestações e interações em veículos especializados em JGD sugere que, ao contrário de
4- O termo churnalism é de difícil tradução. Trata-se da união do substantivo journalism (jornalismo) ao verbo to churn (no sentido figurativo, causar movimento ou agitação

improdutivos).

No contexto do jornalismo, denota a prática de publicar materiais fornecidos por agências de relações públicas, ou outras fontes de informação préproduzida, para aumentar o ritmo de distribuição de notícias ou preencher

lacunas. Neste artigo, optou-se por traduzir churnalism como "jornorréia", unindo o substantivo “jornalismo" e o sufixo greco-latino "réia", indicando corrimento ou fluxo intensos. 
5- Disponível em: http://goo.gl/ L6mOfM. Acesso: 10 mar. 2014. 6- Livro eletrônico sem paginação. 7- Free/Open Source Software, ou seja, Software de Código Aberto/Livre. tecnófilos prontos a sacrificar o trabalho duro da reportagem em favor do conforto da manipulação de uma planilha eletrônica no ambiente climatizado da redação, os jornalistas guiados por dados buscam, através da aproximação com a sociologia e a informática, um resgate da essência da profissão, caracterizada pela missão de atender ao interesse público (GANS, 2003; SCHUDSON, 2003) e pelo compartilhamento da cultura profissional da objetividade e da observação dos valores-notícia (TRAQUINA, 2005).

Ao mesmo tempo, pode-se identificar neste grupo tanto uma tendência à apropriação de tecnologia, incomum entre jornalistas ligados a veículos impressos, televisão, rádio e, mesmo, entre muitos repórteres de veículos digitais, quanto uma disposição a compartilhar know-how. Ambos os traços remetem à cultura hacker e sugerem que o JGD seja uma imbricação entre esta cultura, nativa do campo da informática, e a cultura jornalística. Exemplos dessas manifestações podem ser encontrados em manuais profissionais como os de Gray et al. (2012), Rogers (2011), Mancini (2011) e Meyer (1973), bem como em artigos e comentários publicados em weblogs e fóruns. Um levantamento realizado como preparação para este estudo amealhou mais de cem referências de websites nos quais jornalistas especializados em análise de dados e visualização gráfica

nova cultura, denominada cibercultura (RÜDIGER, 2008). Isto se deu pela abertura de um novo espaço para a ação humana, um espaço virtual cujo suporte são as ondas eletromagnéticas, os cabos de fibra ótica, os discos rígidos, os microprocessadores e outros aparelhos eletrônicos. Um espaço acessível por interfaces que variam dos computadores pessoais, smartphones e tablet computers a aparatos para a experiência da realidade virtual. Neste ciberespaço, as práticas sociais contemporâneas se associam à tecnologia para formar a cibercultura. Esta convergência entre uma socialidade dispersa, efêmera e hedonista típica da

\section{Os pioneiros da apropiação da informática no Ocidente foram os hacker e suas subculturas}

pós-modernidade e as ferramentas de computação e telecomunicações leva a um movimento de apropriação dos aparelhos informáticos e à "perversão" da utilidade planejada pelos fabricantes de tais aparelhos: "Esta apropriação se dá como um método de improvisação, onde os desvios do uso são responsáveis pelos desenvolvimentos na indústria da informática e por sua popularização" (LEMOS, 2002, p. 257). Os pioneiros dessa apropriação da informática no Ocidente foram os membros da cultura hacker e suas subculturas. Com a popularização dos microcomputadores comunicação mediada por computador, engendrou nas últimas décadas uma e acesso à Internet, a cultura hacker, que 
formou a base do imaginário relacionado às redes de computadores, disseminou-se para o restante da sociedade (STREETER, 2011).

Coleman $\left(2013^{6}\right)$ define hackers como "computer aficionados driven by an inquisitive passion for tinkering and learning technical systems, and frequently committed to an ethical version of information freedom". Em seu estudo etnográfico dos hackers envolvidos no movimento $\mathrm{F} / \mathrm{OSS}^{7}$, a autora identificou como principais características dos membros deste grupo social a subscrição a ideais de liberdade de acesso à informação, que levam a uma ética de compartilhamento, e a apropriação de tecnologias, no sentido de compreender seu funcionamento $e$ desenvolver a capacidade de modificálas, para benefício próprio ou coletivo.

A questão que este trabalho se coloca é: serão as práticas de JGD resultado de uma articulação, de um intercâmbio entre a cultura hacker e a cultura profissional jornalística? Com o objetivo de esclarecer esse ponto, são apresentados resultados de uma observação-participante de repórteres praticantes do JGD numa redação brasileira, suplementada por entrevistas semiestruturadas.

\section{Uma aproximação à cultura dos jornalistas guiados por dados no Brasil}

A pesquisa de campo foi realizada em novembro e dezembro de 2012, quando foram entrevistados três jornalistas experientes nas práticas de JGD e levada a cabo a observação, por três dias, da elaboração de uma série de reportagens especiais sobre as eleições municipais do mesmo ano, na redação de um jornal de escopo nacional sediado em São Paulo ${ }^{8}$. O acompanhamento do trabalho dentro da redação foi acertado diretamente com o jornalista responsável pela série de reportagens sobre o financiamento das campanhas municipais de 2012, Repórter 1. Houve aprovação do editor titular do setor - o Repórter 1 está lotado noutro setor da redação e, neste caso, estava apenas colaborando como editor -, que se envolvia com a edição de textos, mas não com a apuração usando técnicas de JGD. A equipe era composta no total por 16 pessoas, sendo 12 delas repórteres em início de carreira, três, editores, e um colaborador externo. Ao todo, três delas tinham experiência anterior com JGD: o Repórter 1 e um colaborador externo, Repórter 2, estão entre os jornalistas mais experientes na área no Brasil. Além disso, um dos repórteres iniciantes já havia aplicado técnicas de JGD em seus empregos anteriores, num jornal do interior de Minas Gerais e noutro, de Belo Horizonte. O período de três dias, no mês de dezembro, coincidiu com o fechamento das reportagens e foi sugerido pelo próprio Repórter 1, sob a justificativa de que seria a época de trabalho mais intenso com dados e visualizações.

No primeiro dia, uma quarta-feira, o Repórter 1 apresentou as linhas gerais do projeto e comentou alguns de seus pontos fracos e fortes. Sua primeira constatação foi que a inexperiência da equipe exigia uma reiteração constante dos princípios da pauta em investigação e uma atenção redobrada aos textos produzidos. Estava
8- Todos os nomes próprios foram transformados em pseudônimos, de modo a proteger a identidade e a privacidade dos entrevistados, de seus associadose das empresas nas quais trabalham. No mesmo espírito, algumas informações sobre os produtos de seu trabalho e suas experiências profissionais anteriores foram omitidas. 
recebendo de seus repórteres textos no formato de relatórios, não de notícias, fato que o levou a questionar a própria capacidade de explicar claramente aos subordinados a prática do JGD - ele foi um dos responsáveis pelo treinamento dos repórteres, além de atuar como seu editor.

Além disso, explicou ser o principal responsável por "limpar" os dados de financiamento de campanha obtidos junto ao Tribunal Superior Eleitoral (TSE). Em primeiro lugar, as planilhas continham informações além da capacidade de manejo pelo software Microsoft Excel. Em segundo lugar, a pauta incluía apenas os dados de candidatos a prefeito e vereador nas capitais brasileiras, mas estes dados são fornecidos pelo TSE numa única planilha com informações de todas as zonas eleitorais do país. Assim, o primeiro passo foi usar um software específico para o gerenciamento de bases de dados, o Microsoft Access, que era oferecido pelo setor de Tecnologia da Informação da empresa jornalística, para "retalhar" a planilha em documentos menores. Em seguida, coube-lhe a tarefa de apagar os dados irrelevantes e gerar uma nova planilha eletrônica para cada capital.

As planilhas produzidas dessa forma foram repassadas à equipe de repórteres, para que realizassem a verificação e correção de erros. Também ficou a

9- No caso, o software para computação estatística R (http:// www.r-project.org), a biblioteca para criação de visualizações em Javascript D3 (http:// d3js.org) e o aplicativo para criação de linhas de tempo Timeline JS (http://timeline.verite. co). cargo da equipe o cruzamento de dados e a identificação das informações que apresentavam valor-notícia. Cada repórter elaborou uma ou mais pautas a partir desses dados e passou a apurálas durante cerca de duas semanas. Todavia, o Repórter 1 era chamado a todo instante por membros da equipe, para tirar dúvidas sobre o uso das ferramentas, ou para ajudar a realizar cálculos e interpretar dados. Enquanto o Repórter 1 usava a maior parte de seu expediente no refinamento da base de dados e construindo visualizações como um gráfico interativo e uma linha de tempo -, o tempo dos repórteres era usado principalmente na realização de entrevistas por telefone e redação de notícias.

O gráfico e a linha do tempo foram gerados pelo próprio Repórter 1, usando programas open source ${ }^{9}$, mas posteriormente retrabalhadas pela editoria de Arte, para melhorar os aspectos estéticos e adequá-los ao projeto gráfico e exigências técnicas do jornal. O uso destes recursos exige um nível avançado de habilidade em informática, embora não demande o conhecimento de linguagens de programação. $O$ Repórter 1 diz saber modificar e criar pequenos trechos de código em algumas linguagens, que procura estudar em seu tempo livre, mas não pode se considerar um programador. De fato, aprende a usar esses recursos conforme a necessidade, como foi presenciado no caso do gerador de linhas de tempo, com o qual o Repórter 1 se engalfinhou grande parte dos dias em que seu trabalho foi observado. Esta linha do tempo foi criada a partir de material coletado por uma colega no acervo do jornal, com o objetivo de contextualizar a discussão sobre financiamento de campanhas proposto pela série de reportagens, trabalho que, em si, tomou a ela mais de dois dias. Finalmente, os problemas técnicos na linha do tempo foram resolvidos com ajuda do colaborador externo, Repórter 2.
A disposição ao autodidatismo, 
demonstrada pelo Repórter 1 e pelo Repórter 2, é um traço característico da cultura hacker. Não apenas ambos debatiam e faziam testes com ferramentas necessárias naquele momento para o andamento das tarefas, como em diversas ocasiões iam à mesa um do outro, ou à do pesquisador, mostrar técnicas ou ferramentas que não tinham relação alguma com o material em desenvolvimento. Os momentos de descontração ao longo do dia de trabalho eram gastos, muitas vezes, em animados debates sobre as vantagens de um ou outro software ou técnica. Noutras ocasiões, o observador e os observados trocaram mensagens por correio eletrônico com referências para ferramentas citadas nesses debates. Também o faziam espontaneamente, quando algum deles se lembrava de um recurso potencialmente útil para o outro. Ambos demonstram um interesse por tecnologias aplicáveis ao jornalismo que beira a paixão. Percebe-se, através dessas ações, o desejo de apropriação da técnica, bem como uma ética de compartilhamento de informação. Estas três características são apontadas por Coleman (2013) como típicas dos hackers.

Num projeto desenvolvido noutra empresa jornalística, o Repórter 2 também confere grande valor à liberdade de informação, concretizada na abertura da base de dados original criada por ele e sua equipe, um mapeamento urbano:

Desde o início, a gente chamou ele de um projeto de dados compartilhados. A ideia era que o cidadão coletasse dados e dividisse esses dados e que esses dados serviriam para a qualidade de vida na cidade. Ao passo que a gente foi conhecendo os modelos de financiamento, a gente foi percebendo que dados, no fundo, são uma coisa valiosa. As pessoas querem arranjar um jeito de ganhar dinheiro com dados. Então, a gente se firmou na proposta de não fazer dinheiro vendendo dados ${ }^{10}$.

Além de praticar o autodidatismo e valorizar a liberdade de informação, características da cultura hacker, o Repórter 2 também evidencia em sua fala o apreço pelo trabalho de reportagem, ao tecer críticas à prática da "pornografia informacional”, isto é, a apresentação de dados sem aprofundamento interpretativo:

O que tenho aprendido e tenho difundido bastante nas oficinas que tenho feito por aí é que... Então, você vê muitas reportagens que são feitas nos jornais, o cara fazendo uma filtragem muito básica. Você pega uma base de dados como a do ENEM. O cara filtra as dez primeiras linhas, "os dez primeiros", "os dez últimos". Mas, se você tem conhecimento para reorganizar essas bases, você pode fazer muitas outras coisas ${ }^{11}$.

O Repórter 2 afirma ter percebido, com a experiência, que os dados não falam por si, mas são apenas o primeiro passo numa investigação jornalística. Lamenta que haja poucos recursos financeiros e mão-de-obra disponível nas redações para o trabalho de apuração em cima das informações coletadas em bases de dados.

É importante saber as ferramentas, mas a análise depende do velho e bom jornalismo. O que eu vejo é que linkar essa visualização, essa interpretação, essa hipótese que surge da visualização com uma reportagem é difícil. Por quê? Porque precisa de dinheiro. A gente não consegue responder no ritmo que gostaria, tem questões ligadas à própria logística do troço. Eu olho o mapa dessa terra xavante lá no meio do Mato Grosso e penso "olha, os
10- Entrevista, 2 de dezembro de 2012.

11- Entrevista, 2 de dezembro de 2012. 
12- Entrevista, 2 de dezembro de 2012.

13- Grupo de entusiastas da informática cujo objetivo é oferecer "um espaço para que indivíduos dos mais diferentes perfis proponham e articulem ideiase projetos que utilizem a tecnologia para fins de interesse da sociedade". Disponível em: https:// www.facebook.com/ transparencia.hacker. Acesso: 10 mar. 2014.

14- A primeira referência ao caso foi feita pelo weblog Públicos, hospedado no portal de $O$ Estado de São Paulo: http://blogs.estadao. com.br/publicos/ hackers-abrem-dadosfechados-do-governode-sp-sobre-salariosde-servidores. Acesso: 18/02/2013.

15- Associação

Brasileira de

Jornalismo

Investigativo.

16- Entrevista, 8 de

novembro de 2012. caras desmataram sete mil hectares só nesse ano, eu preciso mandar alguém lá". Mas mandar alguém lá é mobilizar, pagar uma passagem. Eu vejo que é um trabalho que vai ter que ser feito e vai demandar recursos. $\mathrm{Na}$ verdade, o meu desejo é que os dados empurrem o jornalismo de campo $^{12}$.

No trecho acima, está bastante claro que, na opinião do Repórter 2, a construção ou obtenção de bases de dados é o ponto inicial de um processo de reportagem, cujos passos subsequentes seguem a rotina produtiva de apuração, edição e publicação tradicional do jornalismo.

O Repórter 2 relatou, a título de exemplo, a história de como um membro do grupo Transparência Hacker ${ }^{13}$ descobriu uma forma de extrair dados sobre salários de todos os funcionários do governo do Estado de São Paulo, gerando uma planilha com um milhão de itens. As notícias geradas a partir dessa base de dados nos maiores jornais do Brasil se detiveram no fato de sua criação, transformando-a em acontecimento, sem nenhuma análise das informações disponíveis ${ }^{14}$. Apenas a Folha de São Paulo citou os dados na manchete, mas, mesmo assim, se focou apenas nos salários mais altos, isto é, não produziu uma contextualização embasada em reportagem ou realizou cruzamentos das informações contidas na planilha.

Além do Repórter 2, também foi entrevistada a Repórter 3, uma jornalista paranaense, com mais de dez anos de experiência em reportagem. A entrevista ocorreu na redação do jornal no qual trabalha, em Curitiba. A Repórter 3 também relata ter começado a praticar JGD espontaneamente, por necessidade de seu primeiro emprego, na editoria de política de um jornal local:

Eu comecei a trabalhar nisso sem saber que estava fazendo RAC. Passei quatro anos cobrindo política em Ponta Grossa, Paraná. Então, fiz várias matérias de RAC sem saber que existia esse termo. Sei lá, cruzar o número de eleitores com o número de moradores, para saber se não existem mais eleitores do que moradores na cidade. Fazia coisas assim, usando Excel, sem saber que o nome disso era RAC. Em 2006, fiquei sabendo do congresso da Abraji. Fiz um curso com o [José Roberto] Toledo, sobre RAC. Foi a partir daí que comecei a usar mais o Excel, para várias outras matérias, e a usar o computador como auxílio para o cruzamento de dados, planilhas e tal ${ }^{16}$.

Um detalhe relevante da biografia da Repórter 3 é o fato de sua mãe ser professora de matemática e ela mesma ter dado aulas de reforço a colegas de escola, quando jovem. A repórter tem, portanto, naturalidade no trato com números. Além disso, começou a usar computadores durante a faculdade e afirma ter enxergado, desde então, o potencial da aplicação da informática ao jornalismo, mesmo sem contato formal algum com a noção de RAC. A Repórter 3 também pode, então, ser considerada uma autodidata com tendência à apropriação de tecnologia.

Outro ponto em comum entre sua visão da atividade com JGD e a cultura hacker é a valorização da liberdade de informação, assim como no caso do Repórter 2. Uma das mais importantes reportagens produzidas pela Repórter 3 envolveu a transcrição de dados dos Diários Oficiais da Assembléia Legislativa do Paraná para uma base de dados, um trabalho de oito 
meses, que posteriormente foi colocado à disposição do público, sob a forma de planilhas disponíveis para cópia e uma ferramenta de consulta na Web:

A gente pegou nossa base de dados, e divulgou na Internet. Por quê? Primeiro, porque achávamos que os Diários Oficiais deviam ser públicos. Se a Assembleia não tinha tornado eles públicos, era nosso trabalho tornar. Segundo, a gente tinha uma crença muito grande no jornalismo colaborativo. Eu não tenho como saber que o dono da farmácia de Chupinzinho é funcionário fantasma de algum lugar, mas o cara que mora em Chupinzinho e sabe que o sujeito tem relação com o deputado tal, se jogar o nome do cara lá na Internet, pode encontrar essa pessoa como funcionário fantasma. Então, a gente recebeu, a partir da base de dados, mais de mil e-mails de pessoas que consultaram a base de dados e nos passaram informações. Esse trabalho foi usado pelos concorrentes? Foi! É o mundo, né? A gente chegava ao ponto de achar que era legal os outros jornais usarem nossa base de dados para fazerem matérias. Eles não iam conseguir tomar da gente... A construção era nossa. Era como se a concorrência respaldasse nosso trabalho, ao usar a base de dados ${ }^{17}$.

O trecho acima evidencia outro traço característico da cultura hacker, além da disposição em compartilhar informação: a disposição para o trabalho colaborativo em conjunto com uma coletividade de participantes.

A Repórter 3 também deixou transparecer durante a entrevista que compreende as técnicas de JGD como uma forma de aumentar a eficiência da análise, mesmo, de ampliar suas capacidades para identificar informações dotadas de valornotícia nestas bases de dados, que seriam impossíveis de se enxergar "a olho nu":

Há informações que você não consegue ver, se você não usa RAC. [...] A gente entrevistou a planilha, e a planilha nos deu as respostas. Então, a série seria totalmente diferente, se não fosse a base de dados. Tinha coisas que a gente foi percebendo enquanto ia montando a planilha. Mas os principais personagens... A gente deu um organizar para ver os maiores salários, e os personagens estavam lá! Não foi para atingir esse ou aquele deputado, essa ou aquela situação que era mais fácil de fazer. Sabe? Foi uma coisa bem menos tendenciosa e mais objetiva. Claro, transparente. Entrevista a planilha, e ela te responde ${ }^{18}$.

No trecho acima, a Repórter 3 faz afirmações que podem ser remetidas ao desejo de maior precisão e objetividade no trabalho de reportagem e faz uma relação direta à aplicação da informática no jornalismo com a consecução destes objetivos. Ela parece compartilhar, portanto, dos ideais do JGD, derivados da proposta do Jornalismo de Precisão.

Tomadas em seu conjunto, as observações desta pesquisa de abordagem etnográfica de jornalistas guiados por dados brasileiros, exposta aqui resumidamente, sugere que os profissionais envolvidos na prática do JGD compartilham traços característicos da cultura hacker, como a tendência à apropriação de tecnologia, a valorização da liberdade de informação e a disposição para o trabalho colaborativo. Por outro lado,não apenas estão inseridos nas rotinas produtivas das redações, compartilhando uma visão de mundo comum a jornalistas de outras especialidades, mas parecem conferir grande importância aos valores tradicionais da cultura profissional do jornalismo, a julgar pelas afirmações em favor do trabalho de reportagem e as críticas ao fetiche tecnológico.

\section{Considerações finais}

A hipótese de que o Jornalismo Guiado por Dados se configure como uma imbricação entre a cultura profissional
17- Entrevista, 8 de novembro de 2012. 18- Entrevista, 8 de novembro de 2012. 
jornalística e a cultura hacker se mostra promissora. Entretanto, é necessária a realização de pesquisas que possam comprovar essa relação, para o quê uma abordagem etnográfica dentro da redação parece indicada, por sua aplicação na compreensão antropológica de diferentes culturas e, em especial, por ter se mostrado adequada aos estudos do campo do newsmaking desde a metade do século XX - inclusive no caso do jornalismo em bases de dados, como comprova a compilação de estudos organizada por Paterson e Domingo (2008).

A observação de jornalistas brasileiros praticantes do JGD permitiria compreender como esse conjunto de práticas, nascido no jornalismo de tradição norte-americana, está sendo absorvido nas redações do país. Trata-se de um tema importante, porque o JGD tem sido visto, nos últimos anos, como uma forma de reportagem com grande potencial para o cumprimento da missão de defesa do interesse público por parte da imprensa, assim como uma prática capaz de criar novos caminhos para a narrativa noticiosa e um possível atrativo para uma audiência composta, cada vez mais, por leitores nascidos e criados na cibercultura. Em especial, o JGD é visto como um tipo totalmente novo de jornalismo, por uma minoria de seus proponentes, e como uma colonização indesejada da informática, por alguns profissionais de outras especialidades. Nos dois casos, é preciso desmistificar a relação entre o JGD e a cultura profissional estabelecida, investigando os valores, práticas e discurso dos profissionais engajados neste tipo de reportagem.

\section{Referências bibliográficas}

\section{ANGÉLICO, F. Lei de acesso à informação pública e seus possíveis}

desdobramentos à accountability democrática no Brasil. 2012. 133 f. Dissertação

(Mestrado em Administração Pública e Governo), Escola de Administração de

Empresas de São Paulo, Fundação Getúlio Vargas, São Paulo, 2005.

BARBOSA, S. Sistematizando conceitos e características sobre o jornalismo digitalem base de dados. In: BARBOSA, S. (Org.). Jornalismo digital de terceira geração. Covilhã: Universidade da Beira Interior, 2007.

BARBOSA, S.; TORRES, V.. Extensões do paradigma JDBD no jornalismo contemporâneo: modos de narrar, formatos e visualização para conteúdos. In: Encontro Anual da Compós, 21, Juiz de Fora. Anais... Brasília: Compós, 2012.

COLEMAN, E. G. Coding freedom: the ethics and aesthetics of hacking. Woodstock: Princeton University Press, 2013. Livro eletrônico. 
DINES, A. O papel do jornal: uma releitura. São Paulo: Summus, 1986.

GANS, H. Democracy and the news. Nova York: Oxford, 2003.

GRAY, J.; CHAMBERS, L.; BOUNEGRU, L. The data journalism handbook: how journalists can use data to improve the news. Sebastopol: O'Reilly, 2012.

HOLOVATY, A. A fundamental way newspaper sites need to change. Adrian Holovaty, 6 set. 2006. Disponível em: http://www.holovaty.com/writing/ fundamental-change. Acesso: 17/02/2013.

LEMOS, A. Cibercultura: tecnologia e vida social na cultura contemporânea. Porto Alegre: Sulina, 2002.

MANCINI, P. Hackear el periodismo: manual de laboratório. Buenos Aires: La Crujía, 2011.

MEDITSCH, E. O jornalismo é uma forma de conhecimento?. Biblioteca Online de Ciências da Comunicação, 1997. Disponível em: http://www.bocc.ubi.pt/pag/ meditsch-eduardo-jornalismo-conhecimento.html. Acesso: 26 jun. 2006.

MEYER, P. Precision Journalism: a reporter's introduction to social science methods. Bloomington: Indiana University Press, 1973.

The Future of CAR: Declare Victory and Get Out!. In: When nerds and words collide: reflections on the development of Computer Assisted Reporting. São Petersburgo: The Poynter Institute for Media Studies, 1999. Disponível em: www.unc.edu/ pmeyer/carfuture.doc. Acesso: 20 fev. 2013.

OLIVER, L. \#dendatameet: Why collaboration is at the heart of good data journalism. Journalism.co.uk, 17 mai. 2010. Disponível em: http://www.journalism. co.uk/news-features/-dendatameet-why-collaboration-is-at-the-heart-of-good-datajournalism/s5/a538719. Acesso: 17 fev. 2013.

PARK, R. A notícia como uma forma de conhecimento. In: STEINBERG, Charles. Meios de comunicação de massa. São Paulo: Cultrix, 1972.

PATERSON, C.; DOMINGO, D.. Making online news: the ethnography of new media production. Nova York: Peter Lang, 2008.

ROGERS, S.. Facts are sacred: the power of data. Londres: Guardian Books, 2011.

RÜDIGER, F. Cibercultura e pós-humanismo: exercícios de arqueologia e 
criticismo. Porto Alegre: EDIPUCRS, 2008.

SCHUDSON, M. The sociology of news. Nova York: Norton, 2003.

STREETER, T. The Net Effect: Romanticism, Capitalism, and the Internet. Nova York: New York University Press, 2011.

TRAQUINA, N. Teorias do jornalismo: a tribo jornalística - uma comunidade interpretativa transnacional. V. 2. Florianópolis: Insular, 2005.

TUCHMAN, G. A objetividade como ritual estratégico. In: TRAQUINA, N. (Org.). Jornalismo: questões, teoria e estórias. Lisboa: Vega. 1993.

Este artigo e todo o conteúdo da Estudos em Jornalismo e Mídia estão

disponíveis em https://periodicos.ufsc.br/index.php/jornalismo

Estudos em Jornalismo e Mídia está sob a Licença Creative Commons 2.5 